\title{
Single-nucleotide polymorphisms of the nuclear lamina proteome
}

\begin{abstract}
Familial partial lipodystrophy (FPLD) has been shown to be due to mutations in the $L M N A$ gene encoding nuclear lamins $\mathrm{A}$ and $\mathrm{C}$, indicating that defective structure of the nuclear envelope can produce this unique phenotype. Some patients with inherited partial lipodystrophy have normal $L M N A$ coding, promoter, and $3^{\prime}$-untranslated region sequences. This suggests that the FPLD phenotype is genetically heterogeneous. Among the candidate genes to consider for the non- $L M N A$-associated forms of FPLD are other components of the inner nuclear membrane, such as lamin B1 and B2 and the lamin B receptor. We developed amplification primers for the coding regions of $L M N B 1, L M N B 2$, and $L B R$, which encode lamin B1, lamin $\mathrm{B} 2$, and the lamin $\mathrm{B}$ receptor, respectively. We found no putative disease mutations in any of these proteins in subjects with non-LMNA FPLD, but, through the screening of diseased and normal subjects, we identified several single-nucleotide polymorphisms (SNPs); specifically, five SNPs in $L M N B 1$ and four SNPs in $L B R$. The $L M N B 2$ gene was monomorphic in screening experiments. We conclude that mutations in other constituent proteins of the nuclear envelope are not present in subjects with non- $L M N A$-associated FPLD. However, the identification of amplification primers and SNPs provides tools to investigate these proteins for their association with other phenotypes.
\end{abstract}

Key words Nuclear envelope - Genomic DNA · Sequencing · Complex traits - Lipodistrophy - Diabetes - Muscular dystrophy

R.A. Hegele $(\bowtie) \cdot$ J. Yuen $\cdot$ H. Cao

Blackburn Cardiovascular Genetics Laboratory, John P. Robarts Research Institute, 406-100 Perth Drive, London, Ontario, Canada N6A 5 K8

Tel. +1-519-663-3461; Fax +1-519-663-3789

e-mail: robert.hegele@rri.on.ca

\section{Introduction}

The nuclear envelope is composed of nuclear membranes, pore complexes, and the nuclear lamina (Morris and Manlial 1999). In dividing cells, the orderly dissolution and reconstitution of the nuclear envelope are essential for the perpetuation of genomic information (Morris and Manlial 1999). In non-dividing cells, components of the nuclear envelope mediate bidirectional molecular flow between cytoplasm and nucleus. However, appreciation of the complexity of nuclear envelope function has intensified after recent demonstrations that naturally occurring mutations within $L M N A$, which encodes nuclear lamins $\mathrm{A}$ and $\mathrm{C}$, underlie several autosomal dominant diseases: a form of Emery-Dreifuss muscular dystrophy (EMD2; OMIM 181350), a form of dilated cardiomyopathy (CMD1A; OMIM 115200), and a form of limb girdle muscular dystrophy (LGMD1B; OMIM 159001). In addition, Dunnigan-type familial partial lipodystrophy (FPLD; OMIM 151660) results from mutations in LMNA (Cao and Hegele 2000).

In contrast, no diseases have so far been shown to result from mutations in $L M N B 1, L M N B 2$, or $L B R$, which encode the nuclear envelope proteins lamin B1, lamin B2, and the lamin $\mathrm{B}$ receptor, respectively. Furthermore, there is no information regarding common variants in these genes. LMNB1 has been mapped to human chromosome $5 \mathrm{q}$ (Wydner et al. 1996), spans around $43 \mathrm{~kb}$, consists of 11 exons (Lin and Worman 1995), and has conserved organization compared with other intermediate filament protein genes (Justice et al. 1992; Maeno et al. 1995). $L M N B 2$ has been mapped to $19 \mathrm{p} 13.3$, spans around $13 \mathrm{~kb}$; consists of 3 exons (Giacca et al. 1994), and its product is expressed ubiquitously (Triboli et al. 1987). $L B R$ has been mapped to $1 \mathrm{q} 42.1$, spans around $35 \mathrm{~kb}$, has 13 exons, and its product is expressed widely in differentiated cells (Schuler et al. 1994). We developed a series of genomic DNA amplification primers for the coding sequences of $L M N B 1$, $L M N B 2$ and $L B R$, in order to screen for nucleotide variants in these genes. In screening experiments, we identified five 
single-nucleotide polymorphisms (SNPs) in $L M N B 1$ and four in $L B R$, but none in $L M N B 2$. These SNPs can serve as markers for genetic linkage or association studies, and the amplification primers can facilitate mutation screening for other diseases.

\section{Methods}

Study subjects

Samples from five subjects with typical FPLD, determined by clinical and biochemical criteria - specifically, absence of fat on arms and legs, increased central fat stores with fat neck and face, and hyperinsulinemia - were evaluated. In addition, samples from a DNA archive of 22 clinically normal Caucasian subjects were screened to determine SNP allele frequencies. For SNPs that altered restriction sites, an expanded set of 140 clinically normal Caucasian subjects was studied to determine allele frequencies. The study subjects gave informed consent, and the study was approved by the Ethics Review Panel, University of Western Ontario.

Screening $L M N B 1, L M N B 2$, and $L B R$ genes for DNA variants

In order to amplify coding regions and intron-exon boundaries from genomic DNA, a primer set was developed, using GeneBank sequences (see Table 1). Primer sequences were derived using GeneBank accession numbers L37737 through L37747 (for LMNB1), M94363 and M94362 (for $L M N B 2$ ), and L25932 through L25941 and NM002296 (for $L B R$ ). Primer sequences are shown in Table 1. For each gene, primers were designed to anneal at a single temperature, which allowed for the use of a single amplification apparatus. Amplification conditions were: $94^{\circ} \mathrm{C}$ for $5 \mathrm{~min}$, followed by 30 cycles comprised of $30 \mathrm{~s}$ each at $94^{\circ} \mathrm{C}$, the specific annealing temperature, and $72^{\circ} \mathrm{C}$, ending with a single 10 -min extension step at $72^{\circ} \mathrm{C}$. The specific annealing temperatures were $57^{\circ} \mathrm{C}, 60^{\circ} \mathrm{C}$, and $58^{\circ} \mathrm{C}$ for all amplification reactions for $L M N B 1, L M N B 2$, and $L B R$, respectively.

Genotyping of coding SNPs that affected naturally occurring restriction sites

The LMNB1 A501V SNP was genotyped using the primers F5'-ATCAAGTGTTTGAGTCTCATCGC-3' and R5'-TCTTGATTATACTTGCACAGTGTTCTT-3'. The amplification conditions were: $94^{\circ} \mathrm{C}$ for $5 \mathrm{~min}$, followed by 30 cycles comprised of $30 \mathrm{~s}$ each at $94^{\circ} \mathrm{C}, 57^{\circ} \mathrm{C}$, and $72^{\circ} \mathrm{C}$, ending with a single 10 -min extension step at $72^{\circ} \mathrm{C}$. The resulting fragment was 280 base pairs in length. Digestion of the V501 allele with $B b v$ I produced a single fragment of 280 base pairs, whereas digestion of the A501 allele produced two fragments, with lengths of 193 and 87 base pairs.
These fragments were resolved after electrophoresis in $2 \%$ agarose gels.

The $L B R$ 336C $>\mathrm{T}$ SNP was genotyped using the primers F5'-TAAAGCTCTTTGCCTTCTTCCC-3' and R5'-ACATAAAGCGGAAGACAAAAGG-3'. The amplification conditions were: $94^{\circ} \mathrm{C}$ for $5 \mathrm{~min}$, followed by 30 cycles comprised of $30 \mathrm{~s}$ each at $94^{\circ} \mathrm{C}, 57^{\circ} \mathrm{C}$, and $72^{\circ} \mathrm{C}$, ending with a single 10 -min extension step at $72^{\circ} \mathrm{C}$. The resulting fragment was 278 base pairs in length. Digestion of the 336T allele with $M s p$ I produced a single fragment of 278 base pairs, whereas digestion of the $336 \mathrm{C}$ allele produced two fragments, with lengths of 152 and 126 base pairs. These fragments were resolved after electrophoresis in $2 \%$ agarose gels.

Statistical analysis

SAS version 6.12 (SAS Institute, Cary, NC, USA) was used for statistical analyses. Allele frequencies were determined from electrophoretogram tracings of genomic DNA sequences, except for two SNPs assayed using restriction digestion. We used $\chi^{2}$ analysis to test the deviation of genotype frequencies from Hardy-Weinberg predictions. The nominal level of significance for statistical analyses was $P<0.05$.

\section{Results}

Identification of SNPs

Genomic DNA sequencing experiments in five non$L M N A$-associated FPLD subjects and 22 normal controls uncovered five relatively common SNPs in $L M N B 1$, designated $414 \mathrm{~T}>\mathrm{C}, 852 \mathrm{~T}>\mathrm{C}, \mathrm{A} 501 \mathrm{~V}, 1779 \mathrm{C}>\mathrm{T}$, and $1804 \mathrm{C}>\mathrm{T}$, of which only $L M N B 1$ A501V affected the coding sequence. No genomic sequence variants were detected in $L M N B 2$. Four relatively common SNPs were detected in $L B R$, designated $165 \mathrm{C}>\mathrm{T}, 192 \mathrm{~A}>\mathrm{G}, 336 \mathrm{C}>\mathrm{T}$, and N154S, of which only $L B R \mathrm{~N} 154 \mathrm{~S}$ affected the coding sequence. No other sequence variants were found in any study sample.

\section{SNP frequencies}

The observed genotype frequencies of all SNPs did not deviate from the predictions of the Hardy-Weinberg equation. The allele frequency in Caucasians for each SNP is shown in Table 2.

\section{Discussion}

We report: (1) the definition of primer sets to amplify the coding sequences of $L M N B 1, L M N B 2$, and $L B R$ and (2) the use of these amplification primers for genomic DNA 
Table 1. Amplification of nuclear envelope proteins

\begin{tabular}{|c|c|c|c|}
\hline Gene & $\operatorname{Exon}(\mathrm{s})$ & Primer sequence & Product size \\
\hline \multirow[t]{22}{*}{$L M N B 1$} & \multirow[t]{2}{*}{ Exon 1} & F 5'-GTTTGTGCCTTCGGTCCC-3' & \multirow[t]{2}{*}{$491 \mathrm{bp}$} \\
\hline & & R 5'-CCCCTCCTTGGCTAACGC-3' & \\
\hline & \multirow[t]{2}{*}{ Exon 2} & F 5'-GAAGACCTCAAGTCATCAGTATGG-3' & \multirow[t]{2}{*}{$279 \mathrm{bp}$} \\
\hline & & R 5'-CTATGGCTTAAGGCAGATGAGG-3' & \\
\hline & \multirow[t]{2}{*}{ Exon 3} & F 5'-TTCATTATTAAATGATTGCCATGT-3' & \multirow{2}{*}{$254 \mathrm{bp}$} \\
\hline & & R 5'-CATGTTTAGCTATGACAAAGTCATTC-3' & \\
\hline & \multirow[t]{2}{*}{ Exon 4} & F 5'-CCATGGTAAGTAGCTTGGCTTT-3' & \multirow[t]{2}{*}{$283 \mathrm{bp}$} \\
\hline & & R 5'-ATGTTCATCATGGGAATTGTGA-3' & \\
\hline & \multirow[t]{2}{*}{ Exon 5} & F 5'-AGCTTGAGAATGCCAGACTGT-3' & \multirow[t]{2}{*}{$220 \mathrm{bp}$} \\
\hline & & R 5'-GAGGAGAGTGACATCAGCCC-3' & \\
\hline & \multirow[t]{2}{*}{ Exon 6} & F 5'-GAGATCATAGGTGTACTGTTTCCA-3' & \multirow[t]{2}{*}{$381 \mathrm{bp}$} \\
\hline & & R 5'-TAAAAAGGGTGAGAGGCAAAAA-3' & \\
\hline & \multirow[t]{2}{*}{ Exon 7} & F 5'-CGAGAAGGGCATATGTGTTTTA-3' & \multirow{2}{*}{$290 \mathrm{bp}$} \\
\hline & & R 5'-GGTCATTTATACCTGTTCAGAAGTG-3' & \\
\hline & \multirow[t]{2}{*}{ Exon 8} & F 5'-ATCTTTGAAGTAACACCCCTC-3' & \multirow[t]{2}{*}{$250 \mathrm{bp}$} \\
\hline & & R 5'-AACGGCCATTTCTAAAATGCTT-3' & \\
\hline & \multirow[t]{2}{*}{ Exon 9} & F 5'-ATCAAGTGTTTGAGTCTCATCGC-3' & \multirow[t]{2}{*}{$280 \mathrm{bp}$} \\
\hline & & R 5'-TCTTGATTATACTTGCACAGTGTTCTT-3' & \\
\hline & \multirow[t]{2}{*}{ Exon 10} & F 5'-TGGCAAGAAATGCTGTCTCTTA-3' & $282 \mathrm{bp}$ \\
\hline & & R 5'-CAACCACACTCTTGGTCTTCAT-3' & \\
\hline & Exon 11 & F 5'-GGTATCCCTGTAGTTAAAAGTTTTTGT-3' & $334 \mathrm{bp}$ \\
\hline & & R 5'-CATCTTGCAACAAAGTGTATGGA-3' & \\
\hline$L M N B 2$ & Exon 2 & F 5'-CAGTGCCGCTGAAGATCG-3' & $220 \mathrm{bp}$ \\
\hline & & R 3'-GCTCTCCTCCTCGCCCTC-3' & \\
\hline & Exon 3 & F 5'-CTGAAGCTGTCCCCCAGC-3' & $361 \mathrm{bp}$ \\
\hline & & R 5'-GGATGTACTTGGGCGTGAAC-3' & \\
\hline & Exons 4 and 5 & F 5'-GTCCCTGGAACCAGAGGTGA-3' & $483 \mathrm{bp}$ \\
\hline & & R 5'-CATGTGTATGTGTGTGCACGAG-3' & \\
\hline & Exon 6 & F 5' TAGACACTGTTGTTGCTCAGCC-3' & $406 \mathrm{bp}$ \\
\hline & & R 5'-TTTGACCAAATGGTGAGATGAG-3' & \\
\hline$L B R$ & Exon 1 & F 5'-GATTCAAAAGGTCGAGGAGC-3' & $250 \mathrm{bp}$ \\
\hline & & R 5'-GGGTGGAAGCACTCACCTG-3' & \\
\hline & Exon 2 & F 5'-TAGTGATCAGCCTGTGGAAAAA-3' & $355 \mathrm{bp}$ \\
\hline & & R 5'-AACCGAGCTGAACTGACTATCC-3' & \\
\hline & Exon 3 & F 5'-TAAAGCTCTTTGCCTTCTTCCC-3' & $278 \mathrm{bp}$ \\
\hline & & R 5'-ACATAAAGCGGAAGACAAAAGG-3' & \\
\hline & Exon 4 and 5 & F 5'-TTGCTTGATTCCAAAACAGTAA-3' & 698 bp \\
\hline & & R 5'-CAGTTCACCTTGTGGCAACC-3' & \\
\hline & Exon 6 & F 5'-AAATAAACCAGATTGAAATTTGACC-3' & $244 \mathrm{bp}$ \\
\hline & & R 5'-CAAAACAGAATTACCATAAACGTACC-3' & \\
\hline & Exon 7 & F 5'-TGTATATATGATGGTGATGTGCTTAG-3' & $202 \mathrm{bp}$ \\
\hline & & R 5'-ACTCTGGTCTAATCAGCTTTAACAAA-3' & \\
\hline & Exon 8 & F 5'-TCATGTGAGCCTTGGGTTAATA-3' & 322 bp \\
\hline & & R 5'-ATTCAAATCTGGAAATGGCTGT-3' & \\
\hline & Exon 9 & F 5'-GTAAAGCCTCCTGACTGGGTTT-3' & $254 \mathrm{bp}$ \\
\hline & & R 5'-CCCACTGCTTATTTTTGAATGG-3' & \\
\hline & Exon 10 & F 5'-TAGTGCTAAGGTCTCTGGGGAG-3' & $280 \mathrm{bp}$ \\
\hline & & R 5'-CCCTCACTTTGTGTGCAAGA-3' & \\
\hline & Exon 11 & F 5'-ACAGAAGCTCCTTCTCССТTTC-3' & $306 \mathrm{bp}$ \\
\hline & & R 5'-TCAAAATGGCATGTTTCAAGTA-3' & \\
\hline & Exon 12 and 13 & F 5'-TCATTTTTAAGAGAAATTACAGATGC-3' & $460 \mathrm{bp}$ \\
\hline & & R 5'-CACACAAAGGACACACACACAC-3' & \\
\hline & Exon 14 & F 5'-GAAAATGAAGTACCTTGTGGTTCC-3' & $338 \mathrm{bp}$ \\
\hline & & R 5'-TTTCCTTGTTTTTGCAAATGG-3' & \\
\hline
\end{tabular}

Table 2. Nuclear envelope protein SNP allele frequencies

\begin{tabular}{llcll}
\hline Gene & SNP name & Sample size & Allele frequency & Detection method \\
\hline LMNB1 & $414 \mathrm{~T}>\mathrm{C}$ & 22 & 414C: 0.091 & Direct sequencing \\
& $852 \mathrm{~T}>\mathrm{C}$ & 22 & 852C: 0.045 & Direct sequencing \\
& $\mathrm{A} 501 \mathrm{~V}$ & 140 & V501: 0.014 & BbvI digestion \\
& $1779 \mathrm{C}>\mathrm{T}$ & 22 & 1779T: 0.091 & Direct sequencing \\
& $1804 \mathrm{C}>\mathrm{T}$ & 22 & 1804T: 0.409 & Direct sequencing \\
LBR & $165 \mathrm{C}>\mathrm{T}$ & 22 & 165T: 0.045 & Direct sequencing \\
& $192 \mathrm{~A}>\mathrm{G}$ & 22 & 192G: 0.182 & Direct sequencing \\
& $336 \mathrm{C}>\mathrm{T}$ & 140 & 336T: 0.240 & Msp I digestion \\
& $\mathrm{N} 154 \mathrm{~S}$ & 22 & S154: 0.227 & Direct sequencing \\
\hline
\end{tabular}

SNP, Single-nucleotide polymorphism 
sequencing, which has resulted in: (3) the identification of five novel SNPs in $L M N B 1$ and four novel SNPs in $L B R$, but none in $L M N B 2$. In addition, we have ruled out the presence of coding sequence mutations in these genes in five subjects with FPLD whose $L M N A$ sequence was normal. This latter finding emphasizes the extremely high specificity of the relationship between particular nuclear envelope mutations in $L M N A$ and the disease phenotype (Hegele 2000).

The findings indicate that, while the nuclear lamin proteins might be good candidate genes for non- $L M N A$ associated FPLD, they are not mutated in these patients. The five subjects were each singleton cases from small families, and, thus, linkage analysis could not be performed to determine whether there was linkage to the region on chromosome 1q21 that harbors $L M N A$, or to any other genomic region. Genomic DNA from these subjects will continue to be sequenced as new candidate genes are identified and prioritized for possible involvement in this phenotype.

We did not examine the promoter regions of these candidate genes, and so we cannot absolutely rule out such mutations in the non- $L M N A$-associated FPLD subjects. However, LMNA mutations in FPLD are predominantly missense mutations that affect amino acids near the carboxy terminus. This suggests that some exposed structure of the mature laminar protein is defective in FPLD, possibly affecting several intracellular functions. Thus, at least for the first set of screening experiments, it could be argued that restricting the search for nuclear envelope mutations to those that could affect protein structure was a reasonable strategy, and that such mutations were absent in $L M N B 1$, $L M N B 2$, and $L B R$ in the five FPLD subjects without a $L M N A$ mutation.

At present, no mechanistic data can explain the role of mutant nuclear laminar proteins in disease. Nuclear lamins belong to the intermediate filament multigene family, and participate in DNA replication, organization, nuclear pore arrangement, nuclear growth, and membrane anchorage (Stuurman et al. 1998). In terminally differentiated cells, the $L M N A$ gene products, lamins $\mathrm{A}$ and $\mathrm{C}$, polymerize to form part of the nuclear lamina, a lattice of 10-nm filaments lining the inner nuclear envelope (Fisher et al. 1986). Structural mutations in nuclear lamin proteins could: (a) destabilize the nuclear lamina or (b) impair interactions with chromatin, nuclear proteins, transcription factors, or other cellular proteins, affecting differentiation and/or apoptosis. Differential tissue expression might alter the impact of mutant nuclear lamins (Hegele 2000).
The reagents described in this report could be helpful for screening the $L M N B 1, L M N B 2$, and $L B R$ genes when these become candidates for other phenotypes, through positional cloning, analogy with other phenotypes, or expression data showing changes in response to particular experimental interventions. The SNPs in LMNB1 and $L B R$ could also be helpful in linkage mapping, and for association studies.

Acknowledgments Pearl Campbell provided outstanding technical assistance. Jasper Yuen was the recipient of a University of Western Ontario Summer Research Training Program Award. Dr. Hegele holds a Canada Research Chair in Human Genetics and a Career Investigator award from the Heart and Stroke Foundation of Ontario. This work was supported by grants from MRC Canada (MT13430), the Canadian Diabetes Association (in honor of Reta Maude Gilbert), the Canadian Genetic Diseases Network, and the Blackburn Group.

\section{References}

Cao H, Hegele RA (2000) Nuclear lamin A/C R482Q mutation in Canadian kindreds with Dunnigan-type familial partial lipodystrophy. Hum Mol Genet 9:109-112

Fisher DZ, Chaudhary N, Blobel G (1986) cDNA sequencing of nuclear lamins $\mathrm{A}$ and $\mathrm{C}$ reveals primary and secondary structural homology to intermediate filament proteins. Proc Natl Acad Sci USA 83:6450-6454

Giacca M, Zentilin L, Norio P, Diviacco S, Dimitrova D, Contreas G, Biamonti G, Perini G, Weighardt F, Riva S (1994) Fine mapping of a replication origin of human DNA. Proc Natl Acad Sci USA 91:7119-7123

Hegele RA (2000) Familial partial lipodystrophy: a monogenic form of the insulin resistance syndrome. Mol Genet Metab 71:539-544

Justice MJ, Gilbert DJ, Kinzler KW, Vogelstein B, Buchberg AM, Ceci JD, Matsuda Y, Chapman VM, Patriotis C, Makris A (1992) A molecular genetic linkage map of mouse chromosome 18 reveals extensive linkage conservation with human chromosomes 5 and 18. Genomics 13:1281-1288

Lin F, Worman HJ (1995) Structural organization of the human gene (LMNB1) encoding nuclear lamin B1. Genomics 27:230-236

Maeno H, Sugimoto K, Nakajima N (1995) Genomic structure of the mouse gene (Lmnb1) encoding nuclear lamin B1. Genomics 30:342346

Morris GE, Manilal S (1999) Heart to heart: from nuclear proteins to Emery-Dreifuss muscular dystrophy. Hum Mol Genet 8:1847-1851

Schuler E, Lin F, Worman HJ (1994) Characterization of the human gene encoding LBR, an integral protein of the nuclear envelope inner membrane. J Biol Chem 269:11312-11317

Stuurman N, Heins S, Aebi U (1998) Nuclear lamins: their structure, assembly and interactions. J Struct Biol 122:42-66

Tribioli C, Biamonti G, Giacca M, Colonna M, Riva S, Falaschi A (1987) Characterization of human DNA sequences synthesized at the onset of S-phase. Nucleic Acids Res 15:10211-10232

Wydner KL, McNeil JA, Lin F, Worman HJ, Lawrence JB (1996) Chromosomal assignment of human nuclear envelope protein genes $L M N A, L M N B 1$, and $L B R$ by fluorescence in situ hybridization. Genomics 32:474-478 